\title{
26 Research Square \\ Contributions of disordered eating behaviours and mindful eating to obesity among young female adults
}

Seliz Bagcilar ( $\sim$ sbagcilar@ciu.edu.tr)

Cyprus International University https://orcid.org/0000-0002-0727-8297

\section{Ceren Gezer}

Eastern Mediterranean University: Dogu Akdeniz Universitesi

\section{Research Article}

Keywords: Mindful eating, Eating disorders, Eating behaviour, Obesity

Posted Date: October 12th, 2021

DOl: https://doi.org/10.21203/rs.3.rs-962963/v1

License: (c) (1) This work is licensed under a Creative Commons Attribution 4.0 International License.

Read Full License 


\section{Abstract \\ Purpose}

The aim of the current study was to investigate the relationship between disordered eating behaviours, level of mindful eating and obesity amongst young female adults.

\section{Methods}

Two hundred and twenty-seven female young adults aged 19-35 living in Famagusta in North Cyprus participated in this current study. Mindful Eating Questionnaire (MEQ) and Eating Attitudes Test (EAT)-26 were used for data collecting through face-to-face interviews. Weight and body composition were obtained by body composition analyser and height were obtained by stadiometer. The measurements of neck circumference (NC), waist circumference (WC), hip circumference $(\mathrm{HC})$ were measured by using a non-stretching tape according to standard techniques. Body mass index (BMI), waist-to-hip ratio (WHR) and waist-to-height ratio (WHtR) were calculated.

\section{Results}

The majority of participants $(66.5 \%)$ had less than 20 points on the EAT-26. Overall, the participants with BMI below $18.5 \mathrm{~kg} / \mathrm{m}^{2}$ had the highest MEQ scores, while the participants with BMI above $30.0 \mathrm{~kg} / \mathrm{m}^{2}$ had the lowest MEQ scores $(p<0.05)$. Similarly, statistical significance was found between the MEQ scores of obese and normal weighted participants $(p<0.05)$. A significant negative correlation was found between MEQ scores and BMI, fat mass, WHR, WHtR, NC and WC $(r=-0.216, p<0.01 ; r=-0.234, p<0.01$; $r=-172, p<0.01$ and $r=-0.244, p<0.01, r=-0.145, p<0.05 ; r=-0.238, p<0.05$, respectively).

\section{Conclusion}

Our findings suggest that there is a negative relationship between the level of mindful eating and BMI. The evidence from this study also suggests a positive relationship between the risk of eating disorders and BMI.

\section{Level of Evidence}

Level V, cross-sectional descriptive study

\section{Introduction}


Disordered eating behaviours and unmindful eating are potential risk factors for obesity [1]. Mindful eating, which has been the focus of studies in recent years, defines a non-judgmental awareness of emotional and physical sensations associated with consuming food. [2-5]. In other words, mindful eating is an approach to eating that focuses on participants' sensory awareness and experiences with food [6]. Accompanied by mindfulness, healthier body weight and eating habits can be encouraged; thereby, mindful eating can be used as a key element to prevent obesity [7].

Along with unmindful eating behaviours, obesity is also associated with a disorder in eating behaviours $[8,9]$. Although the aetiology of disordered eating behaviour is not completely clear, it is defined as a condition that may include insufficient or excessive food intake, on the other hand, is based on mental effects and can lead to physical consequences [10]. A large cross-sectional study showed a significant relationship between unhealthy eating habits and obesity amongst obese participants compared to participants with normal weight [11]. The relationship between gender and obesity has been investigated [12]. Women tend to have a higher risk of obesity compared to men $[13,14]$. Likewise, young women are also at greater risk for eating disorders compared to young men [15]. The aim of the current study was to investigate the relationship between disordered eating behaviours, mindful eating and obesity amongst young female adults.

\section{Methods}

\section{Participants}

This cross-sectional study is included 227 female subjects aged 19-35 who were living in Famagusta, North Cyprus. All participants in the study signed the informed consent form and participated in the study voluntarily. The exclusion criteria were as follows: (1) being younger than 19 , (2) being older than 35 , (3) being male, (4) being pregnant and (5) breastfeeding.

The study was approved by the Ethics Committee of Eastern Mediterranean University (No: 2020/06 and Date 29/09/2020). The data collection was carried out from September 2020 to June 2021. The participants were recruited both by word of mouth and by advertisements through social media. Face-toface interviews were conducted using a questionnaire, which was consisted of questions about demographic characteristics and health status. Mindful Eating Questionnaire (MEQ) and Eating Attitudes Test (EAT-26) were used. In addition, anthropometric data were obtained by researchers.

It was determined that a sample size of 203 people would be needed at a $95 \%$ confidence level and a $5 \%$ confidence interval, aiming to have a statistical power of $80 \%$ and above. Considering the unpredictable changes that may cause a decrease in statistical power in the research conditions, it was decided to increase the sample size by approximately $10 \%$ to 227 people.

\section{Eating attitudes test (EAT-26)}


EAT-26 was developed to measure the eating attitudes of participants between the ages of 11-70 and possible disorders in their eating behaviours [16]. The validity and reliability study was adapted into Turkish by Ergüney-Okumuş and Sertel-Berk. The Cronbach's alpha internal consistency coefficient was 0.84, and the test-retest stationarity coefficient was 0.78 . The EAT-26 is a six-point Likert-type scale and has 3 sub-scores: dieting, bulimia and preoccupation, and oral control. Scores of 20 and above from the EAT-26 scale indicate the elevated risk of disorders in eating attitudes [17].

\section{Mindful eating questionnaire (MEQ)}

MEQ was developed to determine the associations between eating behaviour, awareness and emotional state can be questioned [18]. The validity and reliability study was adapted into Turkish by Kose et al.. The Cronbach alpha consistency coefficient was found to be 0.733 . MEQ is a Likert-type scale consisting of 30 questions. The MEQ has 7 sub-scores: disinhibition, emotional eating, eating control, focus, eating discipline, awareness, and interference. The higher the score of the scale indicates the higher the awareness of eating [19].

\section{Anthropometric measurements}

Weight and body composition were measured on a scale (Tanita BC-543, Amsterdam, The Netherlands) and height was measured with a portable stadiometer (Seca 213, Hamburg, Germany). Body mass index (BMI) was calculated from the recorded height and weight. Data from the World Health Organization were used for BMI classification [20]. A BMI below $18.5 \mathrm{~kg} / \mathrm{m}^{2}$ is considered underweight, $18.5-24.9 \mathrm{~kg} / \mathrm{m}^{2}$ is considered normal weight, $25.0-29.9 \mathrm{~kg} / \mathrm{m}^{2}$ is considered overweight, whereas a BMI above 30.0 is considered as obese [20].

Neck circumference (NC) was measured using a graduated tape from the middle point between the base of the neck and the upper part of the sternum. NCs above ${ }^{3} 34 \mathrm{~cm}$ are classified as high risk for abdominal obesity [21]. Waist circumference (WC) was measured halfway between the top of the lateral iliac crest and the lowest rib. The cut-off points for $W C$ are $>80 \mathrm{~cm}$ and $>88 \mathrm{~cm}$, described as risk and high risk, respectively. Hip circumference $(\mathrm{HC})$ was measured at the point yielding the maximum circumference over the buttocks using a tape measure and waist-to-hip ratio (WHR) was calculated. WHR above 0.85 is described as a risk for non-communicable diseases. The waist-to-height ratio (WHtR) were calculated using measured waist circumference and height. Cut-offs for WHtR $<0.50$, between $\geq 0.50$ and $<0.60$, and $\geq 0.60$ are described as no risk, risk and high risk for non-communicable diseases, respectively [22].

\section{Statistical analysis}

Frequency and percentage for qualitative variables and arithmetic mean and standard deviation for quantitative variables were calculated as descriptive statistics. Parametric assumptions, including the 
Kolmogorov-Smirnov test of normality, were controlled and all statistical analyses were performed with non-parametric methods. Kruskal-Wallis test was applied to understand the statistical significance of differences between BMI categories. In case of significance, the Mann-Whitney U test was performed to investigate pairwise group differences. Spearman rho was calculated to analyse the associations between variables. For whole calculations and analysis, SPSS (Version 26.0 for Mac) software was used. Graphs were created using the Microsoft Excel programme. Statistical significance was accepted to be 0.05 .

\section{Results}

A total of 227 female participants with an average age of $27.9 \pm 4.6$ years participated in the study. The average EAT-26 score of participants was $16.8 \pm 10.2$, whereas the average MEQ score of participants was $100.4 \pm 13.6$. As shown, 33.5\% of the participants had 20 or more from EAT-26. As seen in Table 1, the underweighted participants, according to the BMI classification had the highest MEQ scores, while the obese participants had the lowest MEQ scores $(p<0.05)$. Statistical significance was found between the MEQ scores of overweight and normal weighted participants $(p<0.05)$. Likewise, statistical significance was found between the MEQ scores of obese and normal weighted participants $(p<0.05)$. Even there was not found statistical significance, the lowest EAT-26 scores were found amongst the underweighted participants, whereas the highest EAT-26 scores were found amongst the obese participants $(p>0.05)$.

As can be seen in Figure 1, no statistical relation was found between MEQ scores and EAT-26 scores ( $p$ $>0.05)$. According to Figure 2, there was a significant positive correlation between EAT-26 scores and WHtR $(p<0.05)$. On the other hand, no statistical relation was found between EAT-26 scores and BMI, fat mass, NC, WC and WHR $(p>0.05)$. As shown in Figure 3 , there was a significant negative correlation between MEQ scores and BMI, fat mass, WHR and WHtR $(r=-0.216, p<0.01 ; r=-0.234, p<0.01 ; r=-172, p$ $<0.01$ and $\mathrm{r}=-0.244, p<0.01$, respectively). Furthermore, a significant negative correlation was found between MEQ and both NC and WC ( $r=-0.145, p<0.05 ; r=-0.238, p<0.05$, respectively).

\section{Discussion}

The primary purpose of the present study was to investigate the relationship between disordered eating behaviours, the level of mindful eating and anthropometric measurements of the young female participants. Regardless of their anthropometric measurements, the scores of the participants on both scales were examined, and it was determined that the mean of the EAT-26 score was $16.8 \pm 10.2$ and the mean of the MEQ score was $100.4 \pm 13.5$. When compared with similar studies on young female adults carried out elsewhere, the rates of disordered eating behaviours in the present study were higher than those obtained in Bangladesh [23], Nigeria [24], Palestine [25] and the USA [26].

A growing body of literature has investigated the relationship between WHtR and cardiometabolic risk and revealed that higher WHtR indicates the higher risk of cardiometabolic disease [27-30]. Our findings were shown that participants with high WHtR also had high EAT-26 scores $(p<0.05)$. In other words, it 
was determined that participants at increased cardiometabolic risk have a high risk of eating disorders. Another study conducted with young adult women similarly found the relationship between increased WHtR and increased EAT-26 [31]. Conversely, a few studies observed no relationship between WHtR and the risk of disordered eating behaviour in the literature [32-34].

The data of our study were collected during the COVID-19 pandemic. Possible explanations for the increased rate of disordered eating behaviour risk that we have found may be attributed to the COVID-19 pandemic, altered body perception of participants with the effects of media and biological features such as female body hormones. Lockdown measures during the COVID-19 pandemic significantly were impacted the life routines of the world population $[35,36]$. In addition to this, elevated psychological distress and financial difficulties may have negatively affected the eating behaviours during the COVID19 pandemic [37]. Moreover, social distancing, known as one of the main rules of the pandemic, likely increases communication via the internet, which raises exposure to social media and increases the risk of impaired eating habits [38]. Thin-ideal and diet culture-related content on social media were reported as factors raising the risk of unhealthy relationships with food [39-42].

Experiments investigating menstrual cycle phases' effects on food consumption showed that food consumption patterns vary across the menstrual cycle [43-46]. In addition, in several recent studies, it was determined that female reproductive hormones may influence the symptoms of eating disorders [44, 47-50]. However, there no research has been done on factors that may have contributed to eating habits such as social media exposure, the menstrual cycle that affects the hormone levels of participants, and stress levels in this study. Hence, future studies are needed to investigate such factors that may affect the eating behaviours of participants.

The onset and maintenance of overweight and obesity have been associated with low levels of mindful eating $[51,52]$. Similarly, our results were shown an inverse relationship between MEQ score and BMI ( $p<$ 0.01). In other words, a higher MEQ score was associated with lower BMI or vice versa. In a recent study, similar to our result, an increase in BMI in women was associated with a decreased MEQ score [33]. Moreover, fat mass, WHtR, WHR, WC and NC were greater in the participants with low MEQ scores than those with high scores $(p<0.05)$. Recent studies stress the benefits of mindful eating since with this concept participants focus on the increasing awareness of hunger and satiety cues and self-monitoring [53-55]. As a result of an increased level of mindful eating, it is emphasised that the body weights of participants associated with an elevated risk of obesity, may be decreased [56].

Our study has led us to conclude that there is a negative relationship between mindful eating and BMI. Additionally, the evidence from this study suggests a positive relationship between the risk of eating disorders and WHtR. These findings add to a growing body of literature on mindful eating, eating behaviour disorders and their relationship with anthropometric measurements amongst young female subjects. The present findings might have important implications for understanding obesity and its relationship with disordered eating behaviours and low levels of mindful eating. 


\section{Strength And Limits}

Measurement plays a fundamental role in the reproducibility and replicability of research findings. The accuracy and consistency of questionnaires are known as validity and reliability, respectively. In our study, two scales with validity and reliability were administered to assess mindful eating and eating behaviour. Additionally, measurement reliability is a direct indicator of anthropometric data quality. In order to ensure measurement reliability, all measurements made in this study were performed by trained researchers using standardized data collection methods and calibrated equipment.

It is plausible that a number of limitations may have influenced the results obtained. Firstly, the sample was determined by measuring the people living in a small area. It would be more beneficial to work on larger sample size for the validity and reliability of the data obtained. Secondly, since this study was a cross-sectional study and focused on a specific period of time, it is not possible to make inferences from the data to evaluate the cause-effect relationship.

Thirdly, the factors that may affect eating habits, such as social media exposure, menstrual cycle, and stress level were not investigated in our study.

Finally, the factors related to the psychosocial such as stress level, and economic conditions that may affect the nutritional behaviour of participants have not been evaluated by the researchers. It will be a fruitful research direction to the field if researchers do studies that examine these factors in future studies.

\section{What is already known on this subject?}

Most literature to date emphasized that decreased mindful eating and disordered eating behaviours may increase the risk of obesity. In the literature, there is no study found in which the relationship of both parameters with obesity was investigated simultaneously on young adult women living in the region where the study was conducted.

\section{What this study adds?}

Young adult women with high WHtR had higher EAT-26 scores, which indicates a high level of disordered eating behaviours, in the region where the study was conducted. Also, higher mindful eating was associated with decreasing BMI in the participants. Similarly, higher mindful eating was associated with reducing fat mass, WHtR, WHR, WC and NC in the participants. Thus, increasing mindful eating and reducing disordered eating behaviours of young female adults are essential for developing and protecting public health, as they will reduce the risk of obesity.

\section{Declarations}

Funding (information that explains whether and by whom the research was supported) 
Not applicable

\section{Conflicts of interest/Competing interests}

Not applicable

\section{Availability of data and material (data transparency)}

The datasets generated during and/or analysed during the current study are not publicly available due for the protection of personal information that collected after signed informed consent form from participants but are available from the corresponding author on reasonable request.

\section{Code availability}

Not applicable

\section{Authors' contributions}

All authors contributed to the study conception and design. Material preparation, data collection and analysis were performed by Seliz Bagcilar. The first draft of the manuscript was written by Seliz Bagcilar and all authors commented on previous versions of the manuscript. All authors read and approved the final manuscript.

\section{Ethics approval}

The study was approved by the Ethical Board of Scientific Research and Publication of Eastern Mediterranean University, dated 29/09/2020 and numbered 2020/06.

\section{Consent to participate}

Informed consent was obtained from all the participants.

\section{Consent for publication (include appropriate statements)}

Additional informed consent was obtained from all individual participants for whom identifying information is included in this article.

\section{References}

1. Gouveia MJ, Canavarro MC, Moreira H (2019) Associations between Mindfulness, Self-Compassion, Difficulties in Emotion Regulation, and Emotional Eating among Adolescents with Overweight/Obesity. J Child Fam Stud 28:273-285. https://doi.org/10.1007/s10826-018-1239-5

2. Mantzios M, Egan H, Asif T (2020) A Randomised Experiment Evaluating the Mindful Raisin Practice as a Method of Reducing Chocolate Consumption During and After a Mindless Activity. J Cogn Enhanc 4:250-257. https://doi.org/10.1007/s41465-019-00159-y 
3. Rahimi-Ardabili H, Reynolds R, Vartanian LR et al (2018) A Systematic Review of the Efficacy of Interventions that Aim to Increase Self-Compassion on Nutrition Habits, Eating Behaviours, Body Weight and Body Image. Mindfulness 9:388-400. https://doi.org/10.1007/s12671-017-0804-0

4. Keyte R, Egan H, Mantzios M (2020) How does mindful eating without non-judgement, mindfulness and self-compassion relate to motivations to eat palatable foods in a student population? Nutr Health 26:27-34. https://doi.org/10.1177/0260106019888367

5. Tapper K (2018) Mindfulness and craving: effects and mechanisms. Clin Psychol Rev 59:101-117. https://doi.org/10.1016/j.cpr.2017.11.003

6. Nelson JB (2017) Mindful Eating: The Art of Presence While You Eat. Diabetes Spectr 30:171-174. https://doi.org/10.2337/ds17-0015

7. Zervos K, Koletsi M, Mantzios M et al (2021) An Eight-Week Mindful Eating Program Applied in a Mediterranean Population With Overweight or Obesity: The EATT Intervention Study. Psychol Rep 003329412098810. https://doi.org/10.1177/0033294120988104

8. Hayes JF, Fitzsimmons-Craft EE, Karam AM et al (2018) Disordered Eating Attitudes and Behaviors in Youth with Overweight and Obesity: Implications for Treatment. Curr Obes Rep 7:235-246. https://doi.org/10.1007/s13679-018-0316-9

9. Harrison AN, James Bateman CCB, Younger-Coleman NOM et al (2020) Disordered eating behaviours and attitudes among adolescents in a middle-income country. Eat Weight Disord - Stud Anorex Bulim Obes 25:1727-1737. https://doi.org/10.1007/s40519-019-00814-5

10. Kärkkäinen U, Mustelin L, Raevuori A et al (2018) Do Disordered Eating Behaviours Have Long-term Health-related Consequences?: Disordered Eating and Long-Term Health. Eur Eat Disord Rev 26:2228. https://doi.org/10.1002/erv.2568

11. Crovetto M, Valladares M, Espinoza V et al (2018) Effect of healthy and unhealthy habits on obesity: a multicentric study. Nutrition 54:7-11. https://doi.org/10.1016/j.nut.2018.02.003

12. Shah B, Tombeau Cost K, Fuller A et al (2020) Sex and gender differences in childhood obesity: contributing to the research agenda. BMJ Nutr Prev Health 3:387-390. https://doi.org/10.1136/bmjnph-2020-000074

13. Ameye H, Swinnen J (2019) Obesity, income and gender: The changing global relationship. Glob Food Secur 23:267-281. https://doi.org/10.1016/j.gfs.2019.09.003

14. Di Tecco C, Fontana L, Adamo G et al (2020) Gender differences and occupational factors for the risk of obesity in the Italian working population. BMC Public Health 20:706. https://doi.org/10.1186/s12889-020-08817-z

15. Yu Z, Indelicato NA, Fuglestad $P$ et al (2018) Sex differences in disordered eating and food addiction among college students. Appetite 129:12-18. https://doi.org/10.1016/j.appet.2018.06.028

16. Garner DM, Olmsted MP, Bohr Y, Garfinkel PE (1982) The Eating Attitudes Test: psychometric features and clinical correlates. Psychol Med 12:871-878. https://doi.org/10.1017/S0033291700049163

17. Ergüney-Okumuş F, Sertel-Berk H (2020) Yeme Tutum Testi Kısa Formunun (YTT-26) Üniversite Örnekleminde Türkçeye Uyarlanması ve Psikometrik Özelliklerinin Değerlendirilmesi. Stud Psychol 
40:57-78

18. Framson C, Kristal AR, Schenk JM et al (2009) Development and Validation of the Mindful Eating Questionnaire. J Am Diet Assoc 109:1439-1444. https://doi.org/10.1016/j.jada.2009.05.006

19. Kose G, Tayfur M, Birincioglu I, Donmez A (2017) Adaptation Study of the Mindful Eating Questiionnare (MEQ) into Turkish. J Cogn-Behav Psychother Res 1.

https://doi.org/10.5455/JCBPR.250644

20. World Health Organization (2021) Obesity and overweight. In: Obes. Overweight. https://www.who.int/news-room/fact-sheets/detail/obesity-and-overweight. Accessed 7 Aug 2021

21. Ben-Noun LL, Sohar E, Laor A (2001) Neck Circumference as a Simple Screening Measure for Identifying Overweight and Obese Patients. Obes Res 9:470-477. https://doi.org/10.1038/oby.2001.61

22. World Health Organization (2008) Waist Circumference and Waist-Hip Ratio Report of a WHO Expert Consultation. Geneva

23. Al Banna MdH, Brazendale K, Khan MSI et al (2021) Association of overweight and obesity with the risk of disordered eating attitudes and behaviors among Bangladeshi university students. Eat Behav 40:101474. https://doi.org/10.1016/j.eatbeh.2021.101474

24. Fadipe B, Oyelohunnu MA, Olagunju AT et al (2017) Disordered eating attitudes: demographic and clinico-anthropometric correlates among a sample of Nigerian students. Afr Health Sci 17:513. https://doi.org/10.4314/ahs.v17i2.27

25. Saleh RN, Salameh RA, Yhya HH, Sweileh WM (2018) Disordered eating attitudes in female students of An-Najah National University: a cross-sectional study. J Eat Disord 6:16. https://doi.org/10.1186/s40337-018-0204-4

26. Dunn TM, Hawkins N, Gagliano S, Stoddard K (2019) Participants who self-identify as having "orthorexia nervosa" score in the clinical range on the Eating Attitudes Test-26. Eat Weight Disord Stud Anorex Bulim Obes 24:1025-1030. https://doi.org/10.1007/s40519-019-00651-6

27. Gibson S, Ashwell M (2020) A simple cut-off for waist-to-height ratio (0.5) can act as an indicator for cardiometabolic risk: recent data from adults in the Health Survey for England. Br J Nutr 123:681690. https://doi.org/10.1017/S0007114519003301

28. Macek P, Biskup M, Terek-Derszniak M et al (2020) Optimal cut-off values for anthropometric measures of obesity in screening for cardiometabolic disorders in adults. Sci Rep 10:11253. https://doi.org/10.1038/s41598-020-68265-y

29. Savva S, Lamnisos D, Kafatos A (2013) Predicting cardiometabolic risk: waist-to-height ratio or BMI. A meta-analysis. Diabetes Metab Syndr Obes Targets Ther 403.

https://doi.org/10.2147/DMSO.S34220

30. Yoo E-G (2016) Waist-to-height ratio as a screening tool for obesity and cardiometabolic risk. Korean J Pediatr 59:425. https://doi.org/10.3345/kjp.2016.59.11.425

31. Aparecida Silva J, Oliveira Lopes S, Stofeles Cecon R, Eloiza Priore S (2021) Risk behavior for eating disorders in female university students from Viçosa-MG. Rev Assoc Bras Nutr-RASBRAN 12:119- 
132. https://doi.org/10.47320/rasbran.2021.1302

32. Miri N, Noroozi M, Zavoshy R, Ezzeddin N (2019) The Association of Body Image With Anthropometric Measures and Eating Disorders Among Students From University Sports Teams. Int J Epidemiol Res 6:114-119. https://doi.org/10.15171/ijer.2019.21

33. Özkan N, Bilici S (2021) Are anthropometric measurements an indicator of intuitive and mindful eating? Eat Weight Disord -. Stud Anorex Bulim Obes 26:639-648. https://doi.org/10.1007/s40519020-00904-9

34. Borisenkov MF, Popov SV, Pecherkina AA et al (2020) Food addiction in young adult residents of Russia: Associations with emotional and anthropometric characteristics. Eur Eat Disord Rev 28:465472. https://doi.org/10.1002/erv.2731

35. Rigotti T, De Cuyper N, Sekiguchi T (2020) The Corona Crisis: What Can We Learn from Earlier Studies in Applied Psychology? Appl Psychol 69:1-6. https://doi.org/10.1111/apps.12265

36. Brown S, Opitz M-C, Peebles Al et al (2021) A qualitative exploration of the impact of COVID-19 on participants with eating disorders in the UK. Appetite 156:104977. https://doi.org/10.1016/j.appet.2020.104977

37. Simone M, Emery RL, Hazzard VM et al (2021) Disordered eating in a population-based sample of young adults during the COVID -19 outbreak. Int J Eat Disord 54:1189-1201. https://doi.org/10.1002/eat.23505

38. Rodgers RF, Lombardo C, Cerolini S et al (2020) The impact of the COVID -19 pandemic on eating disorder risk and symptoms. Int J Eat Disord 53:1166-1170. https://doi.org/10.1002/eat.23318

39. Worsfold KA, Sheffield JK (2021) Practitioner eating disorder detection: The influence of health mindset, thin-ideal internalization, orthorexia and gender role. Early Interv Psychiatry 15:296-305. https://doi.org/10.1111/eip.12940

40. Aparicio-Martinez P-M, Martinez-Jimenez, et al (2019) Social Media, Thin-Ideal, Body Dissatisfaction and Disordered Eating Attitudes: An Exploratory Analysis. Int J Environ Res Public Health 16:4177. https://doi.org/10.3390/ijerph16214177

41. Hawkins LK, Farrow C, Thomas JM (2020) Do perceived norms of social media users' eating habits and preferences predict our own food consumption and BMI? Appetite 149:104611. https://doi.org/10.1016/j.appet.2020.104611

42. Archibald-Durham L (2021) The insta-diet. Curr Allergy Clin Immunol 34:30-32

43. Hardin SL, Thornton LM, Munn-Chernoff MA, Baker JH (2020) Premenstrual symptoms as a marker of ovarian hormone sensitivity in eating disorders. Int J Eat Disord 53:296-301. https://doi.org/10.1002/eat.23213

44. Hardin SL, Thornton LM, Munn-Chernoff MA, Baker JH (2020) Premenstrual symptoms as a marker of ovarian hormone sensitivity in eating disorders. Int J Eat Disord 53:296-301. https://doi.org/10.1002/eat.23213

45. Kammoun I, Ben Saâda W, Sifaou A et al (2017) Change in women's eating habits during the menstrual cycle. Ann Endocrinol 78:33-37. https://doi.org/10.1016/j.ando.2016.07.001 
46. Arnoni-Bauer Y, Bick A, Raz N et al (2017) Is It Me or My Hormones? Neuroendocrine Activation Profiles to Visual Food Stimuli Across the Menstrual Cycle. J Clin Endocrinol Metab 102:3406-3414. https://doi.org/10.1210/jc.2016-3921

47. Mikhail ME, Culbert KM, Sisk CL, Klump KL (2019) Gonadal hormone contributions to individual differences in eating disorder risk. Curr Opin Psychiatry 32:484-490. https://doi.org/10.1097/YC0.0000000000000543

48. Novelle MG, Diéguez C (2019) Updating gender differences in the control of homeostatic and hedonic food intake: Implications for binge eating disorder. Mol Cell Endocrinol 497:110508. https://doi.org/10.1016/j.mce.2019.110508

49. Castellini G, Lelli L, Cassioli E, Ricca V (2019) Relationships between eating disorder psychopathology, sexual hormones and sexual behaviours. Mol Cell Endocrinol 497:110429. https://doi.org/10.1016/j.mce.2019.04.009

50. Baker JH, Eisenlohr-Moul T, Wu Y-K et al (2019) Ovarian hormones influence eating disorder symptom variability during the menopause transition: A pilot study. Eat Behav 35:101337. https://doi.org/10.1016/j.eatbeh.2019.101337

51. Rossy L (2016) Eating Solution the Mindfulness-Based, proven strategies to end overeating, satisfy your hunger, and savor your life. New Harbinger Publications, Inc., Oakland

52. Czepczor-Bernat K, Brytek-Matera A, Gramaglia C, Zeppegno P (2020) The moderating effects of mindful eating on the relationship between emotional functioning and eating styles in overweight and obese women. Eat Weight Disord - Stud Anorex Bulim Obes 25:841-849. https://doi.org/10.1007/s40519-019-00740-6

53. Manku R, Egan H, Keyte R et al (2020) Dieting, mindfulness and mindful eating:exploring whether or not diets reinforce mindfulness and mindful eating practices. Health Psychol Rep 8:59-67. https://doi.org/10.5114/hpr.2019.88057

54. Carrière K, Khoury B, Günak MM, Knäuper B (2018) Mindfulness-based interventions for weight loss: a systematic review and meta-analysis: Mindfulness interventions for weight loss. Obes Rev 19:164177. https://doi.org/10.1111/obr.12623

55. Fuentes Artiles R, Staub K, Aldakak L et al (2019) Mindful eating and common diet programs lower body weight similarly: Systematic review and meta-analysis. Obes Rev 20:1619-1627. https://doi.org/10.1111/obr.12918

56. Dunn C, Haubenreiser M, Johnson M et al (2018) Mindfulness Approaches and Weight Loss, Weight Maintenance, and Weight Regain. Curr Obes Rep 7:37-49. https://doi.org/10.1007/s13679-0180299-6

\section{Table}

Table 1. Distribution of EAT-26 and MEQ scores according to BMI classification 


\begin{tabular}{lcc}
\hline BMI classification & $\begin{array}{c}\text { Total EAT-26 Scores } \\
(\mathrm{X} \pm \mathrm{SD})\end{array}$ & $\begin{array}{c}\text { Total MEQ Scores } \\
(\mathrm{X} \pm \mathrm{SD})\end{array}$ \\
\hline Underweight & $10.3 \pm 4.3$ & $105.9 \pm 10.0$ \\
Normal & $16.3 \pm 10.1$ & $102.6 \pm 13.5$ \\
Overweight & $18.1 \pm 10.5$ & $95.7 \pm 13.1^{\mathrm{b}}$ \\
Obese & $19.6 \pm 10.0$ & $93.9 \pm 11.6^{\mathrm{a}, \mathrm{b}}$ \\
Total & $16.8 \pm 10.2$ & $100.4 \pm 13.5$ \\
$p$ & 0.099 & 0.001 \\
\hline
\end{tabular}

${ }^{a}$ shows statistical significance from underweight $(p<0.05)$.

${ }^{\mathrm{b}}$ shows statistical significance from normal $(p<0.05)$.

Figures

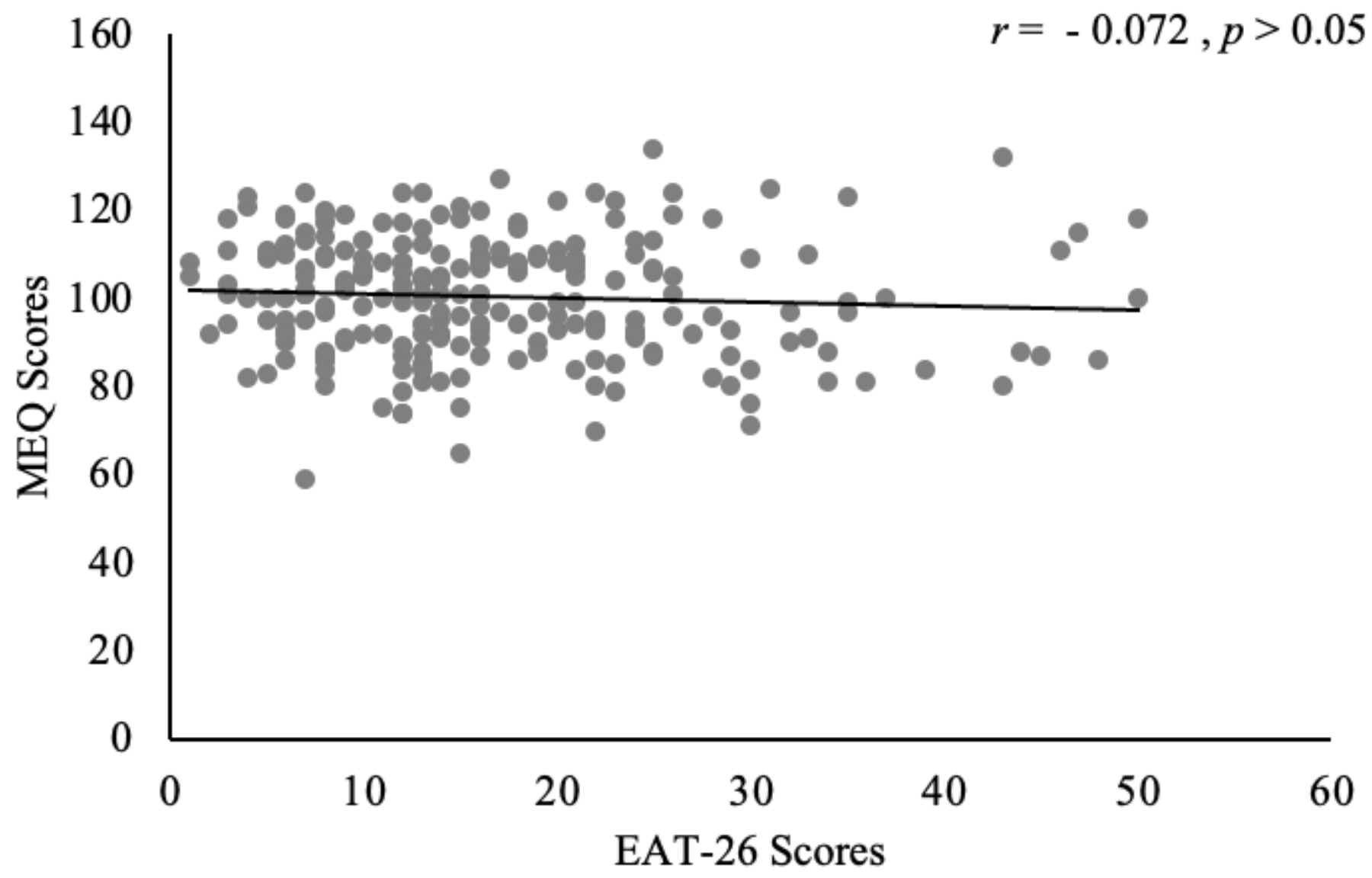

Figure 1

Correlations between EAT-26 scores and MEQ scores 

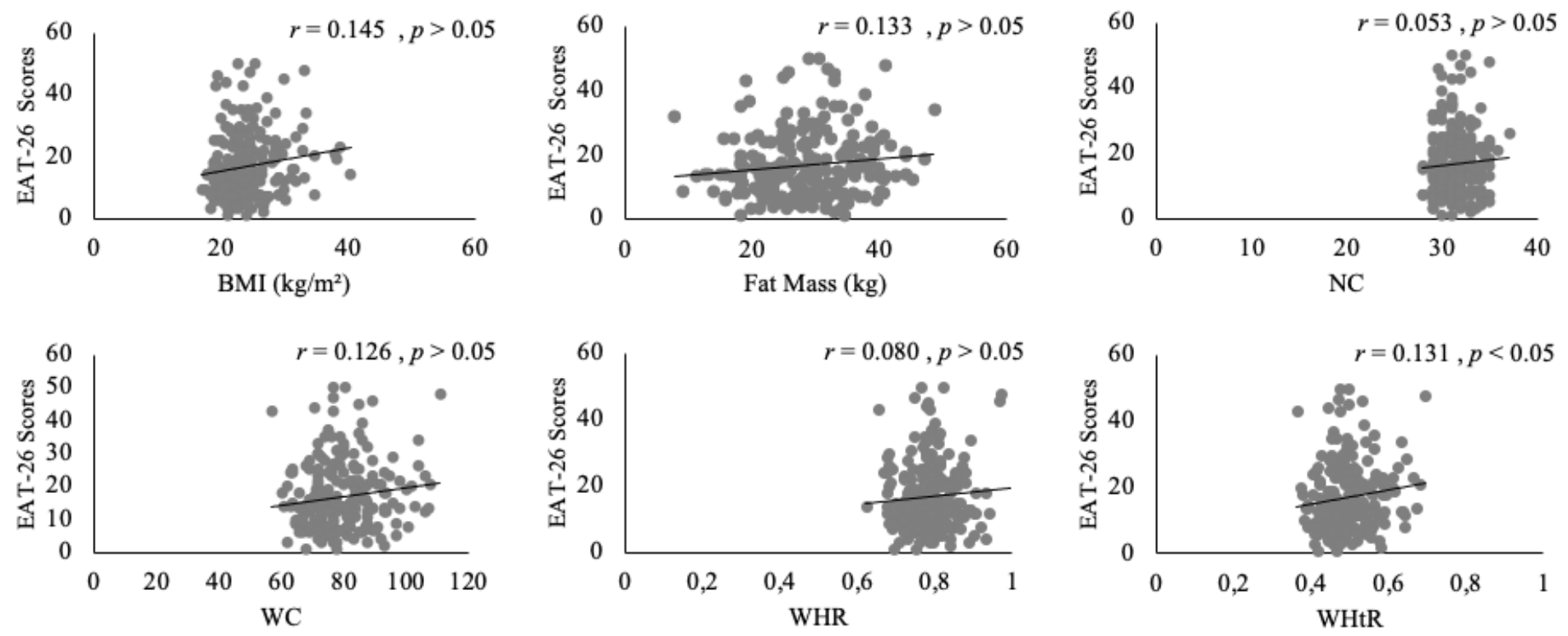

Figure 2

Correlations between EAT-26 scores and anthropometric measurements
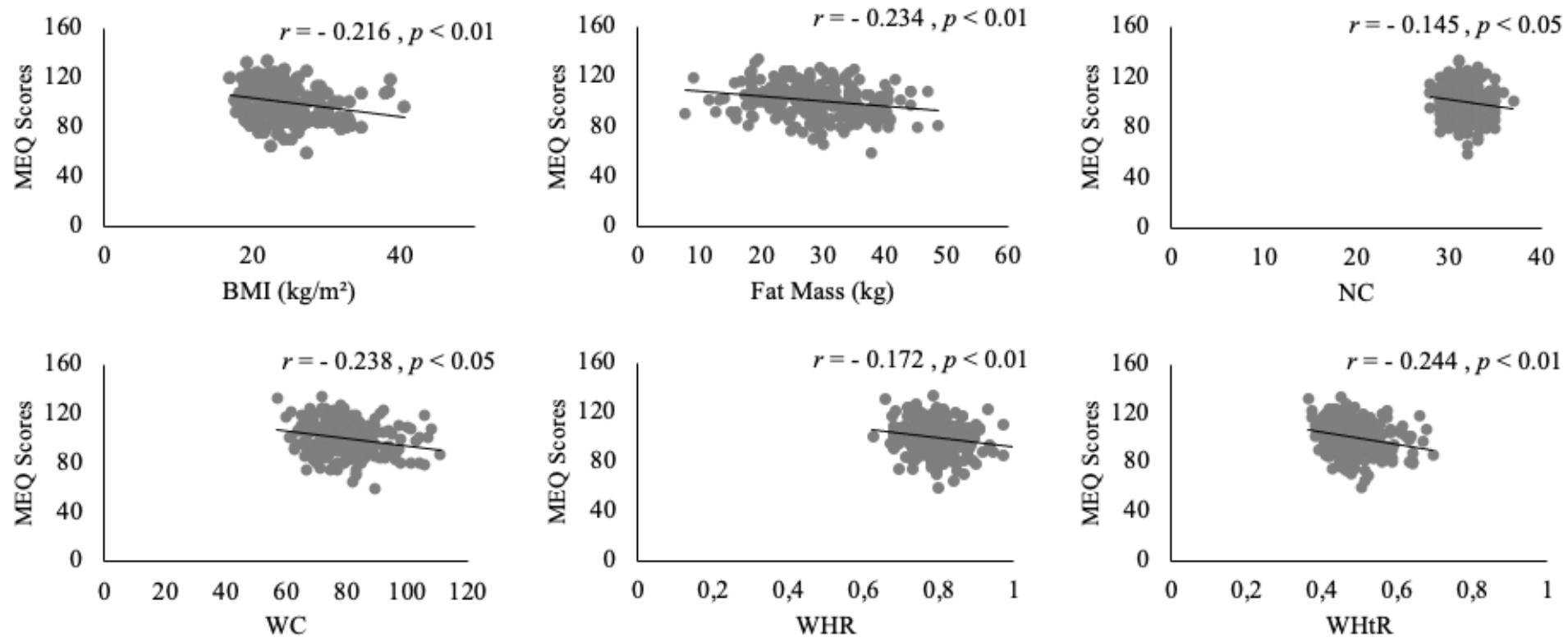

Figure 3

Correlations between MEQ scores and anthropometric measurements 